\title{
"Valuing synergies in strategic mergers and acquisitions using the real options approach"
}

\begin{tabular}{|c|c|}
\hline AUTHORS & $\begin{array}{l}\text { Anna Loukianova } \\
\text { Egor Nikulin } \\
\text { Andrey Vedernikov }\end{array}$ \\
\hline ARTICLE INFO & $\begin{array}{l}\text { Anna Loukianova, Egor Nikulin and Andrey Vedernikov (2017). Valuing } \\
\text { synergies in strategic mergers and acquisitions using the real options approach. } \\
\text { Investment Management and Financial Innovations, 14(1-1), 236-247. } \\
\text { doi:10.21511/imfi.14(1-1).2017.10 }\end{array}$ \\
\hline DOI & http://dx.doi.org/10.21511/imfi.14(1-1).2017.10 \\
\hline RELEASED ON & Friday, 12 May 2017 \\
\hline RECEIVED ON & Tuesday, 07 February 2017 \\
\hline ACCEPTED ON & Wednesday, 29 March 2017 \\
\hline LICENSE & $\begin{array}{l}(c) \text { EY-No } \\
\text { This work is licensed under a Creative Commons Attribution-NonCommercial } 4.0 \\
\text { International License }\end{array}$ \\
\hline JOURNAL & "Investment Management and Financial Innovations" \\
\hline ISSN PRINT & $1810-4967$ \\
\hline ISSN ONLINE & $1812-9358$ \\
\hline PUBLISHER & LLC "Consulting Publishing Company "Business Perspectives" \\
\hline FOUNDER & LLC "Consulting Publishing Company "Business Perspectives" \\
\hline
\end{tabular}

NUMBER OF REFERENCES

36

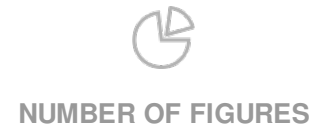

0
NUMBER OF TABLES

0

(C) The author(s) 2023. This publication is an open access article. 
Anna Loukianova (Russia), Egor Nikulin (Russia), Andrey Vedernikov (Russia)

\title{
Valuing synergies in strategic mergers and acquisitions using the real options approach
}

\begin{abstract}
The purpose of the current paper is to elaborate the model for assessing cumulative synergetic effect in M\&A (Mergers and Acquisitions) deals on the basis of a real options approach. The majority of papers on the synergetic effects of M\&A deals typically focus on a particular type of synergy, while the current paper proposes a model that accounts for the cumulative simultaneous effect of different types of operating and financial synergies. The methodology of our research is loosely based on Datar-Mathews real option valuation model, which is flexible and intuitive for practitioners. Formulae for assessing eight types of synergy typically arising from M\&A deals are developed. They are integrated into a single model to assess their cumulative effect on the M\&A deal using a simulation modelling approach. The method was used ex post to find synergy values in two recent M\&A deals in the pharmaceutical industry, and produced sound results. The proposed approach to value target companies could be used by firms before an M\&A deal in the due diligence process. Using this tool a company can build a bidding strategy and define the maximum premium it can pay for the target.
\end{abstract}

Keywords: mergers, acquisitions, synergy, real options.

JEL Classification: G30, G31, G34.

Received on: $7^{\text {th }}$ of February, 2017.

Accepted on: $29^{\text {th }}$ of March, 2017.

\section{Introduction}

Merger and acquisition (M\&A) issues are currently receiving a considerable amount of attention in the corporate finance literature. The main reason for this may be the general increase in M\&A activity all over the world. According to WilmerHale's 2016 M\&A Report, the quantity of M\&A deals worldwide, as well as their value, reached record numbers in 2015. The number of M\&A transactions increased by $4 \%$ from the figure for 2014 to 33,365, while the total value of M\&A deals reached a historic \$3.89 trillion (WilmerHale, 2016).

However, despite the growing popularity of M\&A activity, recent studies have contended that most of the deals do not result in increased value for the acquirer's shareholders. Some authors indicate an unsuccessful rate of 50\% (Weber et al., 2014), while others suggest even higher rate of $70 \%-90 \%$ (Clayton et al., 2011).

The obvious question comes to mind: what makes so many M\&A deals unsuccessful? The general

(C) Anna Loukianova, Egor Nikulin, Andrey Vedernikov, 2017.

Anna Loukianova, Ph.D., Associate Professor, Department of Finance and Accounting, Graduate School of Management, St. Petersburg University, Russia.

Egor Nikulin, Ph.D., Associate Professor, Department of Finance and Accounting, Graduate School of Management, St. Petersburg University, Russia.

Andrey Vedernikov, M.Sc., Graduate School of Management, St. Petersburg University, Russia

This is an Open Access article, distributed under the terms of the Creative Commons Attribution-NonCommercial 4.0 International license, which permits re-use, distribution, and reproduction, provided the materials aren't used for commercial purposes and the original work is properly cited. belief is that the acquirer's managers have failed to find a company that will match the strategic purpose of the acquisition. Consequently, companies often overpay for the deal or fail to conduct the acquisition in the right way (Clayton et al., 2011).

Generally speaking, companies engage in M\&A activity to obtain a particular type (or several types) of synergy (Sehleanu, 2015). Such an effect can be achieved by blending the assets (both tangible and intangible) of the acquirer and the target company. The synergy is reflected in additional value created by unifying the companies. In order for the M\&A deal to be successful, this value should be larger than the value of the stand-alone companies before M\&A.

The synergy can be derived from different sources. The two main types of synergy singled out by many authors are operational and financial (see, e.g., Baldi and Trigeorgis, 2009; DePamphilis, 2010; Devos et al., 2009; Sehleanu, 2015). Operating synergies involve the improvement of companies' operating activities. They can be achieved, because, since the combined firm is bigger than any of the companies before the M\&A deal, it can exert economies of scale, exercise greater pricing power and provide new opportunities for growth in new or existing markets. Financial synergies come from the fact that the merged firm can bring better debt capacity, as well as the tax benefits resulting from operating losses from the target firm, asset revaluations, etc. However, it should be noted that synergy is not automatically achieved after an M\&A deal is made. Instead, companies need to make some effort (and incur some costs) in order to extract the synergy. One of the common recommendations should not wait 
too long to exploit the synergy and to integrate synergy targets into personnel incentive systems (Ficery et al., 2007).

All in all, in order to decrease the probability of a negative outcome from an M\&A deal, it is necessary for an acquirer to assess the expected synergetic effect from the M\&A activity before engaging in it. Although the phenomenon of M\&A has been extensively studied in the literature over recent decades, the main peculiarity of the existing research on M\&A synergies is that it usually focuses on a specific type of synergy (see, e.g., Basmah and Rahatullah, 2013; Bena and Li, 2014). At the same time, it is understandable that the overall result of an M\&A deal is determined by the cumulative impact of several M\&A synergies (Hamza et al., 2016). For this reason, the current paper proposes an approach that takes into consideration the cumulative effect of the eight most common types of M\&A synergy, both operational and financial. The approach is based on the Datar-Mathews real option valuation model, which allows for uncertainty of decision making and can be relatively easily interpreted by practitioners. In order to test the validity of the proposed approach, it was applied to two recent cases of M\&A deals in the pharmaceutical industry.

The paper has the following structure. The first section introduces the concept of synergies that arise from an M\&A deal and discusses the applicability of the real options approach for their assessment. The following sections are devoted, respectively, to a description of the research model, and the results of its application to two recent M\&A cases. At the end of the paper, conclusions of the research and its limitations are highlighted.

\section{Valuation of synergies: real options approach}

According to DePamphilis (2010), synergies from an M\&A deal reflect an additional creation of value that comes from the unification of companies and which would have been impossible without this unification. In other words, an M\&A deal has a positive effect if the process of cooperation between two entities creates additional value that is superior to the value generated by the entities prior to this deal (Sehleanu, 2015).

Synergies are usually divided into two main groups: financial and operational. Operational synergies occur because of the improvement in operating activities of the merged companies. According to Hamza et al. (2016), the operational synergy can be reflected in increased revenue, cost savings, investment cutbacks and greater market power. Many research papers provide empirical evidence for the existence of operating synergies. For example, Kruse et al. (2007) analyzed the operating performance following 69 mergers of Japanese manufacturing firms from 1969 to 1999, and found evidence of improvements in the operating performance of these companies. André and Yen (2007) show that the acquirer firms with controlling shareholders demonstrate the improvement of operating performance for over three years after the M\&A deal. Wang and Fei (2009) demonstrate that the acquisition of poorly governed target companies by firms with good corporate governance systems experience greater operating performance improvements (measured as return on assets).

Financial synergies are created by combining the capital structures of the merged companies, resulting in higher expected cash flows or lower discount rates (Baldi and Trigeorgis, 2009). They can encompass tax benefits or enhanced debt capacity and, as a result, decrease the combined cost of capital of the company. For example, Basmah and Rahatullah (2013) show that some Saudi Arabian firms engage in M\&A deals chasing financial synergy. They look forward to decreasing their overall risk by diversifying their operations and lowering the cost of capital.

The majority of studies on M\&A synergies focus on particular types of synergy or industry (see, e.g., Basmah and Rahatullah, 2013; Bena and Li, 2014; Ghosh, 2001; Halkos and Tzeremes, 2013; Kirchhoff and Schiereck, 2011; Mohanty and Das, 2015). Papers providing empirical evidence for the cumulative effect of different types of synergy as the outcome of an M\&A deal have started to appear only recently (see, e.g., Devos et al., 2009; Hamza et al., 2016). Devos et al. (2009) analyzed a sample of 264 large mergers and found that merger gains accounted for $10.03 \%$ of the combined equity value of the merging firms. The gains were, then, decomposed into operating and financial parts, with the former comprising $8.38 \%$ of the total gain. Hamza et al. (2016) considered a sample of 59 French takeovers between 1999 and 2011. These deals create both operational and financial synergies, with the operational ones being particularly important. According to their conclusions, the main source of operational synergies for the companies considered appears to be investment expenditure cutbacks.

The assessment of target companies before an $\mathrm{M} \& \mathrm{~A}$ is an on-going issue that is reflected in the corporate finance literature. There can be at least two approaches to this problem. Damodaran (2005) exemplifies the first one. The synergetic effects of M\&A deals were included in his basic formula for assessment of value of the target company: 
Value $_{\text {target }}=$ Value $_{\text {targetstand }- \text { alone }}+$ Value $_{\text {synergies }}+$ + ControlPremium.

According to equation (1), the value of the target company consists of three main elements: 1) its stand-alone value; 2) the value of synergies derived via the M\&A deal; 3) a control premium that represents additional money that an acquirer is obliged to pay over the fair stand-alone value of the target company.

In order to account for managerial flexibility connected with an M\&A deal that is reflected in different future potential strategic alternatives, several authors (see, e.g., Baldi and Trigeorgis, 2009; Bruner, 2004) have proposed embedding a real options perspective in the valuation framework. According to Bruner (2004), the value of the target company should be evaluated by the following formula:

Value $_{\text {target }}=$ Value $_{\text {targetstand }- \text { alone }}+$ Value $_{\text {synergiesinplace }}+$

+ Value $_{\text {synergiesrealoption. }}$.

In other words, the main difference between the approaches of Bruner (2004) and Damodaran (2005) is the former's introduction of the category of real options as synergies, which are not explicitly declared in Damodaran's classification. Specifically, Bruner proposes the following categorization of potential real options in acquisition:

- Growth options.

- Exit options.

- Options to postpone investment.

- Flexibility option (to change operating scale).

- Switch option (to change operation processes).

This paper follows the logic of Bruner's approach to valuing target companies. The cumulative effect of eight main operating and financial synergies will be considered.

There are a lot of methods that allow to account for real options in valuation. The methodology of our research will be loosely based on Datar-Mathews method (Mathews et al., 2007). The biggest advantage of Datar-Mathews method is that it connects net present value (NPV) valuation and scenario analysis with a Monte Carlo simulation technique, thus, greatly improving the potential of usage of real options methods in managerial decision making. This method is very flexible, since it can more easily deal with non-lognormal cash flow distributions, multiple uncertainties, and random exercise price than the other methods.

\section{Research methodology}

First, it is necessary to understand which types of synergy are to be assessed, because the specification of parameters depends on the type and characteristics of synergy. Using classifications by Bruner (2004), Damodaran (2005) and Collan et al. (2009) for this research methodology, eight types of synergy are singled out. They are quite typical in M\&A deals and can, therefore, be accounted for by the proposed model.

\section{Operational synergies}

1.1. Revenue enhancing synergies through cross selling, cross branding, etc.

1.2. Cost-reduction synergies through greater purchasing power, capacity utilization, reducing overlapping management.

1.3. Growth synergies. Synergetic effect giving opportunities for higher growth in one of the segments.

2. Financial synergies

2.1. Tax benefits.

2.1.1. Loss carry forward.

\subsubsection{Asset write-up.}

\subsubsection{Tax rate decrease.}

2.2. Increased borrowing capacity / decreased borrowing rate.

\subsection{Decreased cost of capital.}

The general form of the valuation model that is proposed can be presented as follows:

NPV $($ total synergies $)=$ PV $($ costsyn $)+$

$+\mathrm{PV}$ (revenuesyn) + PV (growthsyn) +

$+($ taxsyn $)+($ bcsyn $)+($ drsyn $)-(\mathrm{CI})$,

where PV (revenuesyn) - revenue synergies; PV (costsyn) - cost synergies; PV (growthsyn) growth synergies; PV (taxsyn) - tax synergies; PV (bcsyn) - borrowing capacity synergies; PV (drsyn) - discount rate synergies; PV (CI) - costs of integration.

After $\mathrm{k}$ simulations, NPV values for the total package of synergies are obtained. The value of synergies can be derived as a positive mean of distribution of NPV outcomes:

Value of synergies $=$ Average $[\mathrm{Max}(\mathrm{PV}$ (synergies) - PV (Integration costs), 0)].

After obtaining the combined value of synergies the company can build its bidding strategy according to the following principle:

$\mathrm{IV}+\mathrm{S}>\mathrm{MV}+\mathrm{P}$,

where IV - intrinsic value of the target; $S$ expected value of synergies; MV - market value of target; $\mathrm{P}$ - required premium to acquire the target. 
From the formula above, it can be seen that the target company should be acquired only if its intrinsic value plus acquired value of synergies is greater than the total amount of money the acquirer would pay for the target.

The elaboration of the valuation model requires several main steps:

1. Choosing the probability distribution for synergies and costs of integration.

2. Building formulae to calculate synergies.

3. Doing simulation modelling.

4. Terminating negative values.

The final two steps of the model are technical and will not be considered in detail in the current paper.

\section{Probability distribution.}

In the first stage, one needs to know the probability distribution for values of each type of synergy as a representative of their uncertainty. The type of distribution should reflect the scenarios identified by the managers. The simplest and most intuitive is triangular distribution, which is widely used in corporate finance (Armstrong et al., 2004). It is easy for users to understand, because it requires specifying only minimum, maximum and most probable values for distribution. In our future calculations, this particular type of distribution will be used, although the model does allow for the other types of probability distribution.

The formula for probability density function is as follows:

$$
f(x)= \begin{cases}0, \in & x<a ; \\ \frac{2(x-a)}{(b-a)(c-a)}, & a \leq x \leq c \\ \frac{2(b-x)}{(b-a)(b-c)}, & c \leq x \leq b \\ 0, & x>b\end{cases}
$$

\section{Operational synergies formulae.}

2.1. Cost reduction synergy. Operational cost reduction will lead to an increase in the company's free cash flow (FCF) by size of reduction multiplied by $(1-\operatorname{tax}$ rate). Thus, the present value of incremental benefits from this type of synergy will be determined by the following formula:

$$
P V(\text { costsyn })=\frac{C F_{\text {rand }} \times(1-t)}{r \times(1+r)^{n}},
$$

where - effective tax rate; $r$ - discount rate for the combined company; $n$ - number of years needed to realize the synergy; $C F_{\text {rand }}-$ a distribution of possible cost savings that starts from year $n+1$ defined by the triangular probability density function (according to (6)).
According to equation (7), $\left(C F_{\text {rand }} \times(1-\mathrm{t}) / r\right)$ represents a perpetuity of the amount of operating cost reduction that is, then, discounted back to the present time.

2.2. Revenue synergy. The revenue synergy formula is different in structure from equation (7), because revenue increase will not directly result in a corresponding boost of the company's FCF. The point is that revenue gain will be accompanied by an inevitable increase in costs. Thus the formula for assessment of this synergy will be based on FCF that comes as a percentage of sales (FCFS). In other words, in order to have an increase in FCF as a result of the revenue growth, it is necessary to multiply the increase in revenue by this percentage. FCFS can be calculated for the combined company or for single business segments:

$P V($ revenuesyn $)=\frac{d R_{\text {rand }} \times F C F S}{r \times(1+r)^{n}}$,

where $r$-discount rate for the combined company; $n$ - number of years taken to realize the synergy; $F C F S-F C F$ as a percentage of sales of a business segment (or of the combined company); $d R_{\text {rand }}-\mathrm{a}$ distribution of possible revenue increases starting from year $n+1$ defined by the triangular probability density function.

2.3. Growth synergy. The present value of synergetic effects resulting from revenue growth increase in one of the business segments will be defined by the following formula:

$$
\begin{aligned}
& P V(\text { growthsyn })= \\
& =\sum_{n=1}^{k}\left(\frac{\left(R \times x \times\left(\left(1+g_{2}\right)^{n}-\left(1+g_{1}\right)^{n}\right)\right) \times F C F S}{(1+r)^{n}}\right)+ \\
& +\frac{\left(R \times x \times\left(\left(1+g_{2}\right)^{k}-\left(1+g_{1}\right)^{k}\right)\right) \times F C F S}{r \times(1+r)^{k}},
\end{aligned}
$$

where $R$ - revenue of combined company just before the merger; $x$ - share of business segment of the combined company positively affected by acquisition; $F C F S$ - free cash flow expressed as a percentage of sales of a business segment (or of the combined company); $r$ - discount rate for the cash flows of the combined company; $k$ - number of years the company can sustain increased growth rate; $g_{1}$ - old growth of segment; $g_{2}$ - new growth of segment defined by probability density distribution.

According to (9), the growth synergy assessment is divided into two parts. The first part is derived in the period before moment $\mathrm{n}$, while the second part is derived after moment $\mathrm{n}$ using a perpetuity growth model. 
Financial synergies formulae.

2.4. Tax benefits. NOL carry forwards. Tax benefits arise in M\&A when one of the merging parties has losses, but retains a very low probability of achieving profits in the observable future; thereby it will not be able to realize loss carry forward tax reduction. Merging with a profitable company will open such opportunities. For example, US GAAP allows for the loss to be carried forward for up to seven years and in some cases even up to $15-20$ years (US Code $26 \$ 382$ ).

If the acquirer is confident of being profitable in the future, it may consider calculating tax benefits using classic NPV methods. However, if there is substantial uncertainty, managers can also specify expected tax benefits using triangular distribution and include these in the real option valuation model:

$$
P V(\text { taxsyn_1 })=\sum_{m=1}^{n-k} \frac{\left(N O L \times E_{\text {rand }}\right) /(n-k)}{(1+r)^{m}},
$$

where $k$ is an average "age" of losses; $n$ - number of years when carry-forward is allowed; NOL - total size of accumulated losses; $r$ - discount rate (usually cost of debt or risk free to discount tax benefits); $E_{\text {rand }}-$ coefficient showing which percentage of NOL is allowed to be carried forward, specified using probability density function.

2.5. Tax benefits. Asset write-up. When tax benefits come from potential asset write-up, synergetic effects are derived through higher depreciation deductions and the resulting tax shield. The present value of synergy in this case will be calculated using the following formula:

$$
P V(\text { taxsyn_2 })=\sum_{e=1}^{n} \frac{\frac{K \times A_{1}}{n} t}{(1+r)^{e}},
$$

where $n$ is a useful life of assets in number of years (for the case of linear depreciation schedule); $A_{1}-$ asset value before merger; $t$ - effective tax rate for the combined company; $r$ - discount rate; $K$ probable share of asset appreciation determined by triangular distribution.

2.6. Tax benefits. Effective tax rate decrease. The combined company may also achieve absolute tax benefits resulting from a decrease in the effective tax rate due to geographical distribution, headquarters relocation, asset combinations or other reasons. In this case the formula for synergy calculation would be as follows:

$$
\begin{aligned}
& P V\left(\text { taxsyn_3 }_{-}\right)= \\
& =\sum_{n=1}^{k} \frac{\left(t_{1}-t_{\text {rand }}\right) \times E B T \times\left(1+g_{1}\right)^{n}}{(1+r)^{n}}+ \\
& +\frac{\left(t_{1}-t_{\text {rand }}\right) \times E B T \times\left(1+g_{1}\right)^{k} \times\left(1+g_{2}\right)}{\left(r-g_{2}\right) \times(1+r)^{k}},
\end{aligned}
$$

where $\operatorname{Tax}_{1}$ - tax rate before acquisition; $\operatorname{Tax}_{\text {rand }}-$ distribution of possible tax rates for the combined company; EBT - earnings before taxes of the combined company; $K$ - number of years in horizon period; $g_{1}-$ growth rate of revenue during horizon period; $g_{2}-$ growth rate beyond horizon period (long term); $r$ - discount rate for the combined company.

\subsection{Increased borrowing capacity / decreased} borrowing rate. Decreased borrowing costs mean that less money would be spent on serving debt, leading to a proportional increase in the pre-tax cash flow of the company. The formula for calculation of $\mathrm{PV}$ of the synergy will be as follows:

$$
P V(\text { bssyn })=\frac{\left(i_{1}-i_{\text {rand }}\right) \times D \times(1+g)^{n+1} \times(1-t)}{(r-g) \times(1+r)^{n}},
$$

where $D$ is the market value of debt of the combined company in the year of the merger; $i_{1}-$ borrowing rate before acquisition; $g$ - long-term growth rate for the combined company; $t$ - effective tax rate for the combined company; $r$ - discount rate for the combined company; $n$ - number of years required to realize the synergy; $i_{\text {rand }}-$ borrowing rate after acquisition defined by probability distribution.

2.8. Decreased discount rate for the company. Decrease in the discount rate will inevitably increase the value of combined company. The present value of the synergy can be assessed via the following formula:

$P V(d r s y n)=\frac{F C F \times(1+g)^{n+1}}{R_{\text {rand }} \times\left(1+R_{\text {rand }}\right)^{n}}-\frac{F C F \times(1+g)^{n+1}}{R \times(1+r)^{n}},($

where $F C F$ is the combined cash flow of the company in the year of acquisition; $g$ - long-term growth rate of the combined company; $R$ - discount rate for the combined company before acquisition; $R_{\text {rand }}$ - discount rate for the combined company after acquisition determined by probability distribution.

The next section demonstrates how the research model can be applied to two recent M\&A deals conducted in the pharmaceutical industry. 


\section{Application of the research model to recent M\&A cases}

3.1. Pfizer-Hospira (2015). On 5 February 2015, Pfizer announced a friendly acquisition of the entire share capital of Hospira, a manufacturer and seller of pharmaceutical products. The total value of the acquisition was US\$16,771 million, 39\% of which was the premium. Following the acquisition, Hospira's shares were delisted from the New York Stock Exchange.

The acquirer, Pfizer, is a globally established pharma company with headquarters in New York. It is listed on the New York, London, Swiss and Euronext Stock Exchanges. The mission of the company is to become a premier innovative biopharmaceutical corporation with the purpose of improving the lives of patients. In 2014 alone, Pfizer issued 131 patents in the US and 1,730 patents outside the US. The company has largescale operations serving over 175 markets with 130 distribution network sites and some 200 supply partners.

Hospira was a leading provider of injectable drugs and infusion technologies, with more than 80 years of experience, 19,000 employees and 15 manufacturing plants. It operated in three main segments: sterile injectable pharmaceuticals (SIPs), biosimilars, and devices (infusion, pain management, ambulatory devices). In 2014, the company had revenue of around US\$4.4 billion, $68 \%$ of which was attributed to SIPs and $19 \%$ to devices.

3.2. Rationale for an M\&A deal. According to open sources (Pfizer Investor Presentation, 2015), the rationale for the deal was twofold. Firstly, bending production, procurement and other operations were expected to affect the costs of the combined company. Analysts claimed annual cost reductions of US\$800 million achieved within three years (Pfizer Investor Presentation, 2015).

Secondly, the combined company was expected to benefit from growth synergy. Incremental growth in the sterile injectables sector was projected to be 6\%10\% per year until 2020 (Pfizer Investor Presentation, 2015). Sterile injectable products were already part of Pfizer's Global Established Pharmaceuticals segment, whose revenue had been consistently falling over recent years. This acquisition should, therefore, help Pfizer to reverse this trend, given that Hospira was very strong in sterile injectibles. For Hospira itself, the M\&A deal would enable the company to increase the global scale of its operations.

For this deal, two types of synergy were, therefore, considered: cost synergy and growth synergy. The necessary data for calculations were extracted from the companies' annual reports (Pfizer, 2014; Hospira, 2014).

\section{Cost synergy parameters}

\section{Tax rate}

Effective tax rate for Pfizer $(2014)=$ Provision for taxes/Earnings before taxes $=\$ 3,120$ million $/$ $\$ 12,240$ million $=0.255=25.5 \%$.

Effective tax rate for Hospira (2014) $=$ Provision for taxes / Earnings before taxes $=\$ 27$ million / $\$ 388$ million $=0.186=18.6 \%$.

The effective tax rate (T) for the combined company was computed as follows:

Revenue (Pfizer) (2014) = \$49,605 million; Revenue (Hospira) (2014) $=\$ 4,464$ million.

$\mathrm{T}=25.5 \% \times(49,605 /(49,605+4,464))+$ $18.6 \% \times(4,464 /(49,605+4,464))=25 \%$.

\section{Discount rate}

The weighted average cost of capital (WACC) of the combined company was used in the calculations. First, WACC was calculated for Pfizer, then, for Hospira, and finally, for the combined company. The formula for WACC calculation is as follows:

$$
\begin{aligned}
& W A C C=\operatorname{Re} \times(E /(D+E))+ \\
& +\operatorname{Rd} \times(1-t) \times(D /(D+E)),
\end{aligned}
$$

where Re - cost of equity; E - market value of equity; D - market value of debt; Rd - before tax cost of debt; $\mathrm{t}$ - effective tax rate.

Re for Pfizer was obtained via a CAPM model and equaled $10 \%$ (the calculations are shown in the Appendix). Rd was estimated as: Interest expense / (Short-term debt + Long-term debt) = $\$ 1,360$ million / (\$31,500 million $+\$ 5,140$ million $)$ $=0.037=3.7 \%$. E in December 2014 was $\$ 197$ billion (taken from Thomson Reuters Eikon database), while D was $\$ 36.64$ billion. WACC for Pfizer could, therefore, be estimated as follows: WACC (Pfizer) $=10 \% \times(197 /(36.64+197))+$ $3.7 \% \times(36.64 /(36.64+197)) \times(1-0.255)=8.86 \%$.

Re for Hospira was also obtained via the CAPM model and equalled $11.35 \%$ (the calculations are shown in the Appendix). Rd was estimated as $\$ 86$ million / $\$ 1,756$ million $=0.049=4.9 \%$. $\mathrm{E}$ in December 2014 was $\$ 12$ billion (taken from Thomson Reuters Eikon database), while D was $\$ 1.756$ billion. WACC for Hospira was, therefore, estimated in the following way: WACC (Hospira) $=$ $11.35 \% \times(12 /(12+1.756))+4.9 \% \times(1.756 /(12+$ $+1.756)) \times(1-0.186)=10.41 \%$. 
After this the WACC for the combined company was computed by weighting the corresponding rates of the separate companies according to their size:

WACC $($ Combined $)=8.86 \% \times(233.64 /(233.64+$ $+13.8))+10.41 \% \times(13.8 /(233.64+13.8))=8.95 \%$.

3. Number of years to realize the synergy was declared to be three years by Pfizer analysts (Pfizer Investor Presentation, 2015).

\section{Cost reduction scenarios}

Pfizer analysts provided information on the most probable cost reduction $\mathrm{CR}(\mathrm{mb})=\$ 800$ million (Pfizer Investor Presentation, 2015). As for optimistic (CRopt) and pessimistic (CRpess) scenarios, the following assumptions were made. There is a very low probability that a company will not be able to extract any synergies at all, so CR (pess) was assumed to be $\$ 0$ million. CR (opt) was derived using the historical volatility of the acquirer's costs. Pfizer's costs had low volatility over the previous three years and maximum deviation from average was around $10 \%$. Thus, for the optimistic scenario, we will assume that CR $(\mathrm{opt})=800 \times(1.1)=\$ 880$ million .

To sum up, all parameters for calculation of cost synergy component for Pfizer - Hospira deal are as follows: $\mathrm{t}=25 \%$; $\mathrm{WACC}=8.95 \% ; \mathrm{n}=3$ years; $\mathrm{CR}$ $(\mathrm{mb})=800 \mathrm{mln}$ US $\$$; CR(pess $)=0 \mathrm{mln}$ US $\$$; $\mathrm{CR}(\mathrm{opt})=\$ 880 \mathrm{mln}$ US $\$$.

\section{Growth synergy parameters}

\section{Revenue of combined company (R (Combined))}

$\mathrm{R}($ Combined $)=\mathrm{R}$ (Pfizer, 2014) $+\mathrm{R}$ (Hospira, 2014) $=\$ 49,650$ million $+\$ 4,464$ million $=$ $=\$ 54,114$ million.

2. Share of revenue represented by sterile injectables (SI) segment

This indicator was computed as revenue from SI / total revenue. Revenue from SI (Pfizer) was $\$ 3,277$ million (2014). Revenue from SI (Hospira) was calculated as: $68 \% \times 4,464=\$ 3,036$ million. Share of revenue from SI in the combined company $=$ $=(\$ 3,277$ million $+\$ 3,036$ million $) / \$ 54,114$ million $=$ $=11.7 \%$.

3. Share of free cash flow in sales (FCFS) for Pfizer in 2014

FCF for Pfizer in 2014 was obtained according to the general formula:

$F C F=E B I T \times(1-t)+D \& A-\triangle N W C-C A P E X,(16)$

where $E B I T$ are earnings before interest and taxes; $t$ - tax rate; $D \& A$ - depreciation and amortization; $\triangle N W C$ - change in net working capital; CAPEX capital expenditures. $\triangle \mathrm{NWC}=\mathrm{NWC2014}-\mathrm{NWC2013}=(\$ 57.7$ billion$\$ 18.6$ billion $)-(\$ 56$ billion $-\$ 21.31$ billion $)=\$ 3.5$ billion.

CAPEX $=$ Change in net PPE + D\&A $=\$-0.5$ billion.

FCF for Pfizer in 2014 equalled \$11,656 million.

Share of FCFS is $11,656 / 54,114=23.5 \%$.

4. Discount rate (WACC for combined company) equals $8.95 \%$ (calculated in the previous section)

5. Number of years company can sustain increased growth rate

Analysts from Pfizer claimed that the combined company would grow at an increased rate for five years (2015-2020) (Pfizer Investor Presentation, 2015).

\section{Old growth rate}

The growth of Pfizer in the sterile injectables segment over several years prior to the M\&A deal was close to zero. The corresponding growth rate of Hospira was unstable, for example, $12 \%$ in 2014, but no growth in the previous year. For the purposes of valuation, the average growth rate for the last two years, $6 \%$, was taken.

Growth of SI segment before merger for both companies would be:

GrowthOld $($ weighted $)=0 \times(3,277 /(3,277+3,036))$ $+6 \% \times(3,036 / /(3,277+3,036))=2.9 \%$.

\section{New growth rate}

Pfizer defined three scenarios of growth in the sterile injectables segment following merger with Hospira: the most probable $(\mathrm{G}(\mathrm{mp}))$, optimistic $(\mathrm{G}(\mathrm{opt})$ ) and pessimistic (G(pess)) (Pfizer Investor Presentation, 2015):

- $\mathrm{G}(\mathrm{opt})=12 \%$. The growth rate in this scenario equals the projected SI growth in developing countries (2015-2020).

- $\mathrm{G}(\mathrm{mp})=9 \%$. This is the average projected growth of the SI segment between emerging markets and US (12\% and 6\%).

- $\mathrm{G}$ (pess) $=3 \%$. There is a small possibility that synergy extraction will be unsuccessful and the company will grow at the current combined long-term rate of $3 \%$.

To sum up, all the parameters for calculation of growth synergy component for the Pfizer-Hospira deal are as follows: $\mathrm{R}($ Combined $)=\$ 54,114$ million; share of revenue from SI segment $=11.7 \%$; FCFS $=23.5 \% ; \mathrm{WACC}=8.95 \% ; \mathrm{k}$ (growth years) $=5$; GrowthOld (weighted) $=2.9 \%$; new growth scenarios: $\mathrm{G}(\mathrm{opt})=12 \% ; \mathrm{G}(\mathrm{mp})=9 \% ; \mathrm{G}($ pess $)=3 \%$. 
3.3. Cost of integration. Pfizer did not elaborate on how much would be spent on integration, so the corresponding estimates are based on the Ernst \& Young (EY) survey, which estimated how much had been spent on integrating the target after acquisition (Ernst \& Young, 2014). Using the results of the EY analysis, the assumptions for pessimistic, optimistic and most probable scenarios were made. So, the costs of integration (Coi) for different scenarios are as follows:

- $\operatorname{Coi}(\mathrm{opt})=0.05 \times \$ 17$ billion $=\$ 850$ million .

- $\operatorname{Coi}(\mathrm{mp})=0.1 \times \$ 17$ billion $=\$ 1.7$ billion .

- $\operatorname{Coi}($ pess $)=0.2 \times \$ 17$ billion $=\$ 3.4$ billion .

The simulation modelling was performed with the maximum number of simulations 10,000. Different numbers of simulations resulted in synergies valued at around $\$ 5.9$ billion. In reality, Pfizer paid a premium of around $\$ 5$ billion. According to our valuation model, the acquisition should have increased the value to shareholders, because the calculated synergy was almost $20 \%$ greater than the premium that was paid.

The share price of Pfizer was examined to analyze how it had been affected in the short and medium term by the deal. For several weeks after the announcement day, Pfizer's share price jumped from $\$ 32$ to $\$ 35$; however, a year after the deal (in April 2016) it was around $\$ 33$. We conclude that the deal had no decisive effect on Pfizer, so it may have been fairly priced. The synergetic effects may manifest themselves in the medium term, as the integration process continues.

3.4. Actavis-Allergan (November 2014). This friendly merger of two pharmaceutical companies was announced on 17 November 2014. Actavis paid $\$ 66$ billion ( $\$ 219$ per share) with a massive $64 \%$ one-day premium and a $77 \%$ one-week premium. In 2015, Actavis adopted the Allergan name for the whole merged corporation.

Actavis is one of the leading integrated global pharmaceutical companies involved in the development, manufacturing, sale and distribution of generic, biosimilar and over-the-counter pharmaceutical products. The company operates in 60 countries worldwide and sells 250 genericproduct families and 45 branded products. It has its own global distributor, Anda Inc.

Allergan was a multi-specialty healthcare corporation. It focused on developing, manufacturing and selling pharmaceutical products, biological products, medical services and over-thecounter products. It had a presence in some 100 countries and employed around 11,500 people.
3.5. Rationale for an M\&A deal. The main rationale for Actavis shareholders was to create a high-growth company. High growth was expected to result from the combined vast commercial reach, cross-selling and participation in high-growth BioPharma segments.

Following the deal Actavis planned to increase annual revenue growth rate in the observable future to $10 \%$, and to achieve significant cost reductions and tax savings due to the decreased effective tax rate (Actavis Investor Presentation, 2014). The company claimed that financial benefits from expected synergies would be highly probable, citing the successful record in the previous acquisitions of Actavis, Allergan and their subsidiaries.

As a result, for this deal three types of synergy were considered: cost synergy, growth synergy and tax synergy. The necessary data for calculations were extracted from the companies' annual reports (Actavis, 2013; Allergan, 2013).

\section{Cost synergy parameters}

\section{Tax rate}

The effective 2014 tax rate for Actavis was computed as an average of the tax rates for 2009, 2010, 2011 and 2012, since in 2013 Actavis was not profitable. This was $35.35 \%$.

The effective 2014 tax rate for Allergan= Provision for taxes / Earnings before taxes $=\$ 458$ million / $\$ 1,731$ million $=26.46 \%$.

The effective tax rate (T) for the combined company was computed as follows:

Revenue (Actavis, 2014) $=\$ 8,678$ million; Revenue (Allergan, 2014) $=\$ 5,339$ million.

$\mathrm{T}=35.35 \% \times(8,678 /(8,678+5,339)+26.46 \% \times$ $\times(5,339 /(8,678+5,339))=25.45 \%$.

\section{Discount rate}

As in the Pfizer-Hospira deal, the weighted average cost of capital (WACC) of the combined company was used in calculations.

Re for Actavis was $8.74 \%$ (see Appendix). $\mathrm{Rd}=$ Interest expense / (Short-term debt + Long-term debt $)=\$ 240$ million $/(\$ 8,517$ million $+\$ 535$ million) $=0.0265=2.65 \% ; \mathrm{E}=\$ 66.37$ billion (taken from Thomson Reuters Eikon database); D = $=\$ 9,052$ million.

WACC $($ Actavis $)=8.74 \% \times(\$ 66.37$ billion $/(\$ 66.37$ billion $+\$ 9,052$ million $))+2.65 \% \times(\$ 9,052$ million / $(\$ 66.37$ billion $+\$ 9,052$ million $)) \times(1-$ $0.3535)=7.9 \%$. 
Re for Allergan was $9.1 \%$ (see Appendix). $E=\$ 37.6$ billion (taken from Thomson Reuters Eikon database); $\mathrm{D}=\$ 1,527$ million; $\mathrm{Rd}=4.9 \%$.

WACC $($ Allergan $)=9.1 \% \times(\$ 37.6$ billion $/(\$ 37.6$ billion $+\$ 1,527$ million $))+4.9 \% \times(\$ 1,527$ million / $(\$ 37.6$ billion $+\$ 1,527$ million $)) \times(1-0.2646)=$ $=8.89 \%$.

The WACC for the combined company was then computed by weighting the corresponding rates of separate companies according to their size:

WACC $($ Combined $)=7.9 \% \times(\$ 75.4$ billion / $(\$ 75.4$ billion $+\$ 39.13$ billion $))+8.89 \% \times(\$ 39.13$ billion $/(\$ 75.4$ billion $+\$ 39.13$ billion $))=8.24 \%$.

3. Number of years to realize the synergy was declared to be three (Actavis Investor Presentation, 2014).

\section{Cost reduction scenarios}

Actavis analysts claimed that cost reductions should be no lower than $\$ 1,350$ million, so in the most probable scenario, $\mathrm{CR}(\mathrm{mb})=\$ 1,350$ million and in the optimistic scenario, $\mathrm{CR}(\mathrm{opt})=\$ 1,500$ million (according to the costs volatility of Actavis for the previous three years). There was a very low probability that the company would not be able to extract synergies, so CR(pess) was assumed to be $\$ 0$ million.

The parameters for calculation of the cost synergy component are, therefore, as follows: $\mathrm{T}=25.45 \%$; $\mathrm{WACC}=8.24 \% ; \mathrm{n}=3$ years; $\mathrm{CR}(\mathrm{mb})=\$ 1,350$ million; $\mathrm{CR}($ pess $)=\$ 0$ million; $\mathrm{CR}(\mathrm{opt})=\$ 1,500$ million.

\section{Parameters for growth synergy}

\section{Revenue of combined company $(R$ (combined))}

$\mathrm{R}$ (combined) $=\mathrm{R}$ (Actavis, 2013) $+\mathrm{R}$ (Allergan, 2013 $)=\$ 8,678$ million $\$+\$ 6,197.5$ million $=$ $=\$ 14,876$ million .

2. Share of revenue affected by an $M \& A$ deal $\approx$ $100 \%$ (Actavis Investor Presentation, 2014).

\section{FCFS for Actavis for 2013}

$\Delta \mathrm{NWC}=\mathrm{NWC2012}-\mathrm{NWC2011}=(\$ 4,105$ million - $\$ 1,808$ million $)$ - (\$3,518 million - \$2,292 million $)=\$ 1,071$ million .

CAPEX $=$ Change in net PPE + Depr $=1616-$ $-1485+202=\$ 333$ million.

FCF $(2013$, Actavis $)=\$ 656$ million .

FCF was negative at that time for Actavis, so cash flow from operations was taken as a proxy for calculation of FCFS. FCFS was, then, computed as $\$ 1,214$ million $/ \$ 8,678$ million $=14 \%$.
4. Discount rate (WACC for combined company) equals $8.32 \%$ (calculated in the previous section).

5. Number of years company can sustain increased growth rate

Analysts from Actavis assumed the period "observable future" for the purpose of valuation was ten years (2015-2025) (Actavis Investor Presentation, 2014).

\section{Old growth rate}

Analysts from Actavis claimed that the company would have grown as a standalone company at only 8\% over the same period (Actavis Investor Presentation, 2014).

\section{New growth rate}

Actavis claimed $10 \%$ to be the minimum growth rate for the combined company, so we will take it as the most probable rate, i.e., $\mathrm{G}(\mathrm{mp})=10 \%$. There is a very low probability that in the case of wrong integration or other unexpected events, synergy will not be realized and the growth would stay the same, i.e. $\mathrm{G}$ (pess) $=8 \%$. In the optimistic course of events the combined company would grow at the rate of Allergan's main segments, that is $\mathrm{G}(\mathrm{opt})=14 \%$.

To sum up, all the parameters for calculation of the growth synergy component are as follows: $\mathrm{R}$ (combined revenue) $=\$ 14,876$ million; share of revenue affected by the merger is $100 \%$; FCFS $=$ $14 \% ; \mathrm{WACC}=8.24 \% ; \mathrm{k}$ (growth years) $=10$; GrowthOld (weighted) $=6 \%$; new growth rate: $\mathrm{G}(\mathrm{opt})=14 \% ; \mathrm{G}(\mathrm{mp})=10 \% ; \mathrm{G}($ pess $)=6 \%$.

Tax synergy

Tax synergy was assessed according to (16) with the following assumptions:

1. When calculating earnings before taxes (EBT) for the combined company for 2013, the rate average of EBT(2011) and EBT(2012) of Actavis was used because EBT(2013) of this company was negative due to very high investments in working capital and CAPEX.

$\mathrm{EBT}($ Actavis $)=(\operatorname{EBT}(2011)+\mathrm{EBT}(2012)) / 2=$ $=\$ 351$ million.

EBT $(2013)=$ EBT $($ Actavis $)+$ EBT $($ Allergan, 2013 $)=351+1731=\$ 2,082$ million .

2. Horizon period $(\mathrm{k})$ - number of years in horizon period is 10 as stated above.

3. Growth rate during the horizon period $\left(\mathrm{g}_{1}\right)$ is assumed to be $10 \%$.

4. Growth rate beyond horizon period, long term $\left(g_{2}\right)$ is assumed to be $3 \%$. 
5. WACC (calculated in previous section) equals $8.32 \%$.

6. Tax rate before merger ( $\mathrm{t}$ ) equals $25.45 \%$.

7. New tax rate scenarios: $\mathrm{T} 2(\mathrm{mp})=15 \%$; $\mathrm{T} 2($ pess $)=25 \%($ will not change $) ; \mathrm{T} 2(\mathrm{opt})=14 \%$ (exceeding expectations).

As a result, parameters for tax synergy model are as follows: $\mathrm{EBT}=\mathrm{US} \$ 2,082 \mathrm{mln} \$ ; \mathrm{k}=5$ years; $\mathrm{g}_{1}=$ $10 \% ; \mathrm{g}_{2}=3 \% ; \mathrm{WACC}=8.24 \% ; \mathrm{T}=25.45 \%$; $\mathrm{T} 2(\mathrm{mp})=15 \% ; \mathrm{T} 2$ (pess) $=25 \% ; \mathrm{T} 2(\mathrm{opt})=14 \%$.

3.6. Cost of integration. Since Actavis has disclosed no figures for costs of integration, the results of the EY survey were again used to calculate the cost of integration scenarios for the deal.

- Coi $($ opt, $5 \%)=0.05 \times 37.6$ billion $=\$ 1,880$ million.

- Coi $($ most prob, $10 \%)=0.1 \times 37.6$ billion $=$ $\$ 3,760$ million.

- Coi (pess, $15 \%)=0.15 \times 37.6$ billion $=\$ 5,640$ million.

The obtained data were used for Monte Carlo simulation to obtain the expected value of synergies arising from this deal. For 10,000 simulations, the model produced an estimate of the total set of synergies of around $\$ 22.4$ billion. In fact, Actavis paid around \$28.7 billion of premium. If Allergan's intrinsic value at the time of the deal did not significantly differ from its market value, then, it would mean that Actavis overpaid around \$6.3 billion. The most important synergy in this deal according to our valuation model proved to be growth synergy.

To assess the market reaction to this M\&A deal, Actavis's stock price was examined. During the first months after the announcement of the deal, Actavis's share price increased from around $\$ 260$ to over $\$ 310$ per share. However, after the deal the share price started to drop and descended to $\$ 216$ as of April 2016. It can be argued that the deal eventually failed to increase the shareholders' value in the medium term, explained by overpayment for Allergan.

\section{Conclusions}

The goal of the current paper was to elaborate the model for assessing cumulative synergetic effect in M\&A deals on the basis of a real options approach. The incorporation of real options into the valuation framework is feasible, because it enables managerial flexibility in executing different strategic alternatives arising from a particular M\&A deal.

The synergies that can be derived from an M\&A deal are generally divided into financial and operating ones. The majority of papers on the synergetic effects of M\&A deals typically focus on a particular type of synergy, while the most recent studies reveal that the integral outcome of an M\&A deal depends on a combination of operating and financial synergies. The current paper, therefore, proposes a model that accounts for the cumulative simultaneous effect of different types of operating and financial synergies.

The model assessment is loosely based on the Datar-Mathews method, which requires simulation modelling. As a result of its implementation, a probability distribution of NPV of cash flows resulting from an M\&A deal can be derived and, then, analyzed by managers. The proposed model enables evaluation of the cumulative effect of up to eight of the most common types of synergy, either simultaneously or separately.

The model was applied to two recent M\&A deals in the pharmaceutical industry: Pfizer-Hospira and Actavis-Allegan. In the first case, it demonstrated that the premium that Pfizer paid for Hospira was smaller than the cumulative value of synergies. This implies that the market should have reacted positively to such a deal. However, the stock price of Pfizer did not change significantly during the year after the M\&A deal was made. This fact suggests that the deal was not considered a failure by the market, while its positive effect could be manifested over a longer period of time. In the second case, the model showed that the premium that was paid by Actavis was larger than the cumulative value of synergies. Perhaps this was one of the factors that caused the company's share price to drop more than $\$ 40(17.7 \%)$ in 18 months following the M\&A deal.

The model that is proposed here is not free of limitations. First, the number of synergies considered was limited to eight. However, this list is not comprehensive, as the model allows the addition of potential extra synergies from a specific M\&A deal. Secondly, all the calculations that we performed were based on the triangular probability density function that is widely used in corporate finance. At the same time, it should be noted that the model allows the use of other types of probability distribution that might be preferable for some types of synergy or M\&A deal. Thirdly, the applicability of the model proposed was tested via the analysis of a stock price change only, while some other performance indicators could be used for this purpose. Undoubtedly, stock price is a speculative indicator that is influenced by a great number of factors, some of which are outside companies' control. Nevertheless, we believe that an M\&A 
deal is a significant event in a company's activities, which is why it should affect the stock price over a particular period of time.

All in all, the model proposed could be considered as one of the first attempts to evaluate the cumulative synergetic effects derived from an M\&A deal. It is general and allows the use of different assumptions about the number of synergies and type of probability distribution. It can, therefore, be used by practitioners as a convenient, intuitively clear tool for fast estimation of expected M\&A effects for a pool of companies of different industrial affiliations.

\section{References}

1. Actavis. (2013). Annual Report, 10-K. Refrieved from http://phx.corporateir.net/External.File?item= UGFyZW50SUQ9NTM5MDk2fENoaWxkSUQ9MjI4NjI0fFR5cGU9MQ==\&t=1 (accessed 17 November 2016).

2. Actavis Investor Presentation. (2014). Creating the most dynamic company in "Growth Pharma", November 1, 2014. Refrieved from http://phx.corporate-ir.net/External.File?t=1\&item=VHlwZT0yfFBhcmVudElEPTUx NzYwMjV8Q2hpbGRJRD01NjE1Mjk (accessed 15 November 2016).

3. Allergan. (2013). Annual Report, 10-K. Refrieved from http://www.allergan.com/miscellaneous-pages/allerganpdf-files/2013annualreport (accessed 17 November 2016).

4. André, P., and Yen, T. (2007). Ownership structure and operating performance of acquiring firms: The case of English-origin countries. Journal of Economics and Business, 59(5), 380-405.

5. Armstrong, M., Galli, A., Bailey, W., and Couët, B. (2004). Incorporating technical uncertainty in real option valuation of oil projects. Journal of Petroleum Science and Engineering, 44(1-2), 67-82.

6. Baldi, F., and Trigeorgis, L. (2009). Assessing the value of growth option synergies from business combinations and testing for goodwill impairment. Journal of Applied Corporate Finance, 21(4), 115-124.

7. Basmah, A. Q., and Rahatullah, M. K. (2013). Financial synergy in mergers and acquisitions in Saudi Arabia, Finance - Challenges of the Future Yea, XIII(15), 181-192.

8. Bena J., and Li, K. (2014). Corporate innovations and mergers and acquisitions. Journal of Finance, LXIX(5), 1923-1960.

9. Black, F. and Scholes M. (1973). The pricing of options and corporate liabilities. Journal of Political Economy, 81(3), 637-654.

10. Boyle, P. P. (1977). Options: A Monte Carlo approach. Journal of Financial Economics, 4(3), 323-338.

11. Brandão, L. E., Dyer, J. S., and Warren J. H. (2005). Using binomial decision trees to solve real-option valuation problems. Decision Analysis, 2(2), 69-88.

12. Bruner, R. F. (2004). Applied mergers and acquisitions. Hoboken, NJ: J. Wiley.

13. Clayton, C., Alton, R., and Rising, C. (2011). The big idea: The new M\&A playbook. Harvard Business Review, March.

14. Collan, M., Fullér, R., and Mezei, J. (2016). A fuzzy pay-off method for real option valuation. Journal of Applied Mathematics and Decision Sciences, 2009, 1-14.

15. Cox, J. C., Ross, S. A., and Rubinstein, M. (1979). Option pricing: A simplified approach, Journal of Financial Economics, 7(3), 229-263.

16. Damodaran, A. (2005). The value of synergy (working paper), New York: Stern School of Business.

17. DePamphilis, D. (2010). Mergers, acquisitions and other restructuring activities. Burlington: Academic Press Advanced Finance Series.

18. Devos, E., Kadapakkam, P. R., and Krishnamurthy, S. (2009). How do mergers create value? A comparison of taxes, market power, and efficiency improvements as explanations for synergies. Review of Financial Studies, 22(3), 1179-1211.

19. Dixit, A. K., and Pendyck, R. S. (1994). Investment under uncertainty. Princeton, NJ: Princeton University Press.

20. Ernst \& Young. (2014). The right combination: Managing integration for deal success. Refrieved from www.ey.com (accessed 16 November 2016).

21. Ficery, K., Herd, T., and Pursche, B. (2007). Where has all the synergy gone? The M\&A Puzzle. Journal of Business Strategy, 28(5), 29-35.

22. Ghosh, A. (2001). Does operating performance really improve following corporate acquisitions? Journal of Corporate Finance, 7(2), 151-178.

23. Halkos, G. E, and Tzeremes, N. G. (2013). Estimating the degree of operating efficiency gains from a potential bank merger and acquisition: A DEA bootstrapped approach. Journal of Banking \& Finance, 37, 1658-1668.

24. Hamza, T., Schaier, A., and Thraya, M. H. (2016). How do takeovers create synergies? Evidence from France. Studies in Business and Economics, 11(1), 54-72.

25. Hospira. (2014). Annual Report, 10-K. Refrieved from https://www.sec.gov/Archives/edgar/data/1274057/ 000127405715000012/hsp-201410xk.htm (accessed 13 November 2016).

26. Kirchhoff, M., and Schiereck, D. (2011). Determinants of M\&A success in the pharmaceutical and biotechnological industry. IUP Journal of Business Strategy, VIII(1), 25-50.

27. Kruse, T., Hun, Y., Kwangwoo, P., and Suzuki, K. (2007). Long-term performance following mergers of Japanese companies: The effect of diversification and affiliation. Pacific-Basin Finance Journal, 15, 154-172.

28. Mathews, S., Vinay, D., and Johnson, B. (2007). A practical method for valuing real options: The Boeing approach. Journal of Applied Corporate Finance, 19(2), 95-104. 
29. Mohanty, L., \& Das, B. (2015). Pre- and post-merger financial analysis of industry-wise firms in India: An empirical study. XIMB Journal of Management, 12(II), 75-94.

30. Pfizer. (2014). Annual Report, 10-K. Refrieved from http://www.pfizer.com/system/files/presentation/2014_ Pfizer_Financial_Report.pdf (accessed 13 December 2016).

31. Pfizer Investor Presentation. (2015). Acquisition of Hospira, February 5, 2015. Refrieved from http://www.pfizer. com/system/files/presentation/HospiraAnnouncement020515FINAL.pdf (accessed 11 December 2016).

32. Samis, M., and David, G. A. (2014). Using Monte Carlo simulation with DCF and real options risk pricing techniques to analyse a mine financing proposal. International Journal of Financial Engineering and Risk Management, 1(3), 264-281.

33. Sehleanu, M. (2015). Creating or destroying value through mergers and acquisitions? Annals of the University of Oradea. Economic Science Series, 24(1), 593-600.

34. Wang, C., and Fei, X. (2009). Corporate governance transfer and synergistic gains from mergers and acquisitions. Review of Financial Studies, 22(2), 829-858.

35. Weber, Y., Tarba, S. Y., and Sandquist Oberg, C. (2014). A comprehensive guide to mergers \& acquisitions. Upper Saddle River, NJ: FT Press.

36. WilmerHale. (2016). 2016 M\&A Report. Refrieved from https://www.wilmerhale.com (accessed 10 November 2016).

\section{Appendix}

Cost of equity calculation for Pfizer

$\mathrm{Rf}=2.29 \%$ (Average yield on treasury securities with different maturities).

Beta $($ Pfizer $)=0.89$.

$\mathrm{Rm}=11 \%$ (S\&P500 Annualized Return).

$\operatorname{Re}=2.29+0.89 \times(11-2.29)=10 \%$.

Cost of equity calculation for Hospira

$\mathrm{Rf}=2.29 \%$ (Average yield on treasury securities with different maturities).

Beta $($ Hospira $)=1.04$.

$\mathrm{Rm}=11 \%$ (S\&P500 Annualized Return).

$\operatorname{Re}($ Hospira $)=2.29+1.04 \times(11-2.29)=11.35 \%$.

Cost of equity calculation for Actavis

$\mathrm{Rf}=2.29 \%$ (Average yield on treasury securities with different maturities).

Beta $($ Actavis $)=0.74$.

$\mathrm{Rm}=11 \%$ (S\&P500 Annualized Return).

$\operatorname{Re}=2.29+0.74 \times(11-2.29)=8.74 \%$.

Cost of equity calculation for Allergan

$\mathrm{Rf}=2.29 \%$ (Average yield on treasury securities with different maturities).

Beta $($ Allergan $)=0.78$.

$\mathrm{Rm}=11 \%$ (S\&P500 Annualized Return).

$\operatorname{Re}($ Allergan $)=2.29+0.78 \times(11-2.29)=9.1 \%$.

Note: all beta coefficients were taken from the Bloomberg database. 